\title{
ERRATUM
}

Anastasia Zikou · Maria-Christina Ioannidou

Meropi Tzoufi · Loukas Astrakas

Maria I. Argyropoulou

\section{Magnetization transfer ratio measurements of the brain in children with tuberous sclerosis complex}

Published online: 7 October 2005

(C) Springer-Verlag 2005

\section{Pediatr Radiol (2005) 35:1071-1074}

In the Discussion section, second paragraph, line 13:

"... seems to be the cause of low ADC" should read

"... seems to be the cause of high ADC".

The original version of this article is available on http://dx.doi.org/ $10.1007 / \mathrm{s} 00247-005-1539-\mathrm{y}$

A. Zikou · M.-C. Ioannidou · L. Astrakas

M. I. Argyropoulou ( $\square)$

Department of Radiology, Medical School,

University of Ioannina, 45110 Ioannina, Greece

E-mail: margyrop@cc.uoi.gr

Tel.: + 30-2651-0-97733

Fax: + 30-2651-0-97862

M. Tzoufi

Child Health Department, Medical School,

University of Ioannina, Ioannina, Greece 